\title{
BUSINESS RISK MANAGEMENT IN GOVERNMENT: PITFALLS AND POSSIBILITIES
}

\author{
Christopher Hood and Henry Rothstein
}

\section{Introduction}

1.1. Business risk management, taking a variety of forms, has been a growth point in corporate management in recent years. That change in emphasis is said to stem from responses to high-profile disasters like Bhopal and Exxon Valdez, increasing legal and regulatory pressure on risk management and a search for new approaches to formulating corporate strategy. ${ }^{1}$

1.2. Risk management of many types is well-established in the public sector, in domains as various as the management of offenders, health-care systems, tax audits and the operations of weapons systems. ${ }^{2}$ Risk management has always been central to strategic planning in defence, internal security and foreign affairs. ${ }^{3}$ But risk management systems in government tend to be policy-domain-specific. Most are directed towards policy rather than 'business' risks ${ }^{4}$ and some are focused on risks to third parties rather than risks to producer organisations. ${ }^{5}$ Accordingly, if the various private-sector business risk approaches raise issues for the design of institutional routines in government, the issue concerns how far a generic approach to factoring risk into decision-making at senior managerial level is appropriate across government.

1.3. In principle a case could be made for a more generic approach that involved the integration of business risk management techniques into management control and organisational strategy in the public sector. Many of the environmental and technological changes causing risk management to assume greater importance in business strategy (like increased litigation risks, risks of IT failure, financial risks arising from global markets) affect governments as well as business. There is evidence that the 1999 Turnbull ICAEW report on internal control has influenced public as well as private sector developments. Inquiries into government decision making often produce examples of risks being taken with public money or the quality of public services without adequate strategic consideration at senior management level or careful contingency planning. Yet public servants are almost equally often berated for being too risk-averse and not sufficiently

\footnotetext{
${ }^{1}$ See Anderson 1999; Tritton 1999; Power 1999; ICAEW 1999.

2 The variety of ways in which different government organisations assess risk and set standards has been documented by ILGRA in several reports (HSE 1996, 1998).

${ }^{3}$ See Frei and Ruloff 1989.

${ }^{4}$ There are exceptions to this pattern. One is the generic focus on risk management introduced by the Regulatory Impact Assessment Unit and its predecessors. Another is the focus on business risk management and organisational controls developing in the NHS (NHS 1999). A third is the traditional policy-advisory craft skill of higher civil servants and political advisers in spotting political risks, based on unwritten lore rather than explicit procedures.

${ }^{5}$ By policy risk we mean risks relating to the achievement of public policy objectives (like economic policy aimed at stable growth without inflation). By business risks we mean risks to the continued existence or financial status of a particular organisation (like risks of insolvency or fraud). By systemic risk we mean risks affecting an industry or set of organisations (like risks of general banking collapse), as distinct from risks to the position of any individual organisation.
} 
entrepreneurial. ${ }^{6}$ A business risk management approach offers the possibility for striking a judicious and systematically argued balance between risk and opportunity in the form of the contradictory pressures for greater entrepreneurialism on the one hand and limitation of downside risks on the other that are experienced by contemporary public sector managers. ${ }^{7}$

\section{Equivalences between Private and Public Sector Risk Management.}

2.1. If a generic business risk management approach for the public sector is needed, how should it be developed? Should it be 'home-grown', building on public-sector-specific experience and problems? Or should it be read across from developing business models? The latter 'read across' option is not straightforward, for two reasons. One, what counts as 'business risk management' in the private sector varies across different business domains and professionals (like bankers, insurers, accountants). Two, to the extent that risk management models in business have common features, translating them for government may be problematic. Most risk management approaches in business include at least three features for which no exact equivalence is found in government (see Figure 1):

(a) They are aimed at the enterprise (or profit centre) as the primary decision unit.

(b) They conceive risk mainly in terms of shareholder value to the organisation and the various factors that can either add to or detract from that value (like reputation, operations, etc.). ${ }^{8}$

(c) They seek to develop decision aids and tools of discovery (like risk webs and risk maps) to assis t risk identification, assessment and management and link it with general corporate strategy. ${ }^{9}$

2.2. To read across feature (a) above to government, we might equate agencies, bureau's or other budget centres with business firms. Those organisations certainly have important business risks (like IT failure or litigation risks) to manage and some strategic management routines and units to which business risk approaches can be applied. At the same time, many public services delivered to citizens involve several public-service organisations. Accordingly, if the 'business' on which the risk focus is to be laid is on the service to citizens or clients rather than on the well-being of any one organisation, there is a case for a cross-organisational approach to risk management concerned with services or particular hazards. An example of the latter focus is found in the management of risk (of reoffence) posed by registered sex offenders on release from custody, a risk which is

\footnotetext{
${ }^{6}$ More specifically they are sometimes accused of tending to commit 'Type II' rather than 'Type I' errors in risk management, i.e. to prefer errors of commission to errors of omission, especially in regulation (see Brennan 1992; Durodie 1999; and contrast Shrader-Frechette 1991. For a definition of these types of errors see Royal Society 1992: 139-40).

${ }^{7}$ The institutional processes required would belong to a family of systems designed to balance rival desiderata that are commonly found in public sector management (cf. Dunsire 1978; Hood 1996).

${ }^{8}$ Less sophisticated business risk approaches deal only with compliance, prevention, crisis aversion or general operating performance.

${ }^{9}$ A range of approaches is available (at least in part responding to the 1999 ICAEW Turnbull report), including 'bottom-up' processes to identify organisational risks (as in KPMG's risk self-assessment approach) and topdown approaches (see Hanley 1999). The latter include risk mapping (as in PwC's business risk management framework), scenario planning and a variety of approaches intended to identify risk factors across different parts of an organisation (as in the integrated process approach used by Arthur Anderson and AIRMIC or Zurich International's portfolio-management approach).
} 
assessed and managed through multi-organisational committees convened by the police and also involving probation services and local authority housing and social services.

2.3. To read across feature (b) above to government, it has become conventional in public management to equate shareholder value with 'public value' ${ }^{10}$ in the sense of 'results citizens value'. ${ }^{11}$ Public value so defined is more diffuse than shareholder value in business in that it relates to substantive public wants as well as conventional 'value for money' considerations, ${ }^{12}$ and gauging public value is not like painting by numbers. ${ }^{13}$ Moreover, a focus on public value rather than shareholder value also tends to move the business-risk emphasis away from potential damage to, or opportunity for, particular organisations and towards risks to services or from particular hazards. More generally, it raises the question of how far the accent on risk management in the public sector should be laid on systemic risk (little considered in private-sector corporate risk management in practice) as against risks to the survival, financial position or reputation of individual organisations.

2.4. To read across feature (c) above to government, business risk management needs to be incorporated into planning routines and key decision processes. But decision-making over business risk in government often differs from that applying to the conventional company board setting in at least two ways. First, strategic decisions affecting risk in the public sector are frequently dispersed across multiple organisations and routines. Arguably that feature makes the need for 'integrated process' approaches to business risk management if anything more potentially relevant to government than to private firms, but it implies a multi-organisational rather than single-enterprise focus. Second, whereas company board decisions over high-level strategy are normally made behind the screen of commercial confidentiality, ${ }^{14}$ government decision-making is subject to strong and rising expectations of transparency and public accountability. This feature raises tricky questions of how public-sector business risk management can be conducted in a way that secures frank consideration of potential threats and opportunities.

\footnotetext{
${ }^{10}$ Moore 1995

${ }^{11}$ Barzelay 1992.

12 In parliamentary democracies it is conventional to regard the final arbiters of public value as voters and elected representatives. Beyond that, public value might be equated with general public values relating to public services as revealed by opinion polling or focus-group discussions.

${ }^{13}$ For instance, there is a difference between informed and uninformed public opinion, between deliberative and non-deliberative opinion surveying, and (most difficult in ethical analysis) between what gains popular support or opposition and what deserves to. Such differences are often crucial to what is to be counted as public value in the management of technical risks that are unfamiliar to the general public.

${ }^{14}$ It is possible that the development of risk management approaches, associated with regulatory changes and the guidance on reporting on the effectiveness of internal control systems to shareholders, may increase the transparency of private-sector decision processes. If so, it would mean a two-way transfer of routines and styles between government and business rather than a one-way transfer.
} 


\section{Figure 1. Equivalences Between Private and Public Sector Risk Management}

\section{Source Domain: \\ Private Sector Risk Management}

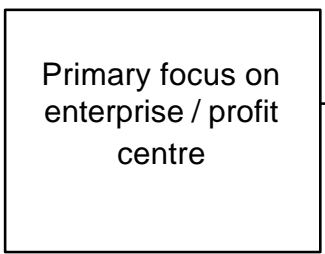

Target Domain:

Public Sector Risk Management

Possible Equivalent

Agency, bureau or budget centre as

focus of business risk management

\section{Alternative or Difference}

Focus on services or hazards involving several organisations

\section{Possible Equivalent}

Focus on risk to each organisation's financial viability, operational capacity, reputation etc.

conceived in

relation to shareholder value of enterprise

Alternative or Difference

Focus on Public Value and on Systemic Risk as well as 'Organisational Risk'

Possible Equivalent

Business Risk Management approaches developing as heuristic frameworks to aid corporate strategy (mostly in top-down mode) within an information regime of commercial confidentiality.

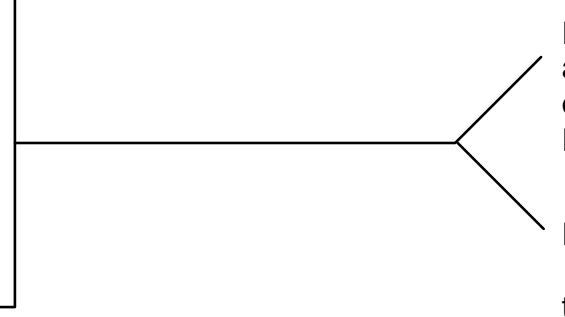

Focus on developing business risk management at management board level or equivalent in public organisations within an information regime of Freedom of Information

\section{Alternative or Difference}

Focus on developing business risk management at multiple levels (starting with the cabinet) and through multiple routines (e.g. Procurement Regime, Regulatory Impact Regime etc.)

\section{Potential Pitfalls of Inappropriate Risk Management in Government.}

3.1. It was suggested earlier that business risk management approaches could be used as a systematic way of balancing the pressures on public managers to be entrepreneurial risktakers and the pressures on them for prudence and risk-avoidance. But if inappropriately applied, risk management could produce negative side-effects by accentuating already strong blame-avoidance imperatives in public organisations. ${ }^{15}$ Among the potential pitfalls of inappropriately applied risk management, three are identified below (see Figure 2), and are illustrated in the 'street festival' example given at the end of this paper.

3.2. Business risk management primarily designed to limit liability or avoid blame to particular public organisations could obstruct appropriate systemic risk management. Risk management systems need to be carefully designed if they are not to encourage public service organisations to shuffle blame on to others. Effective policy delivery in many domains requires different public organisations to work together - a theme that has been much stressed by the current UK government and requires cross-organisational trust and managerial 'craftsmanship' of a high order. ${ }^{16}$ Systems that put too much stress on limiting downside business risk at organisational level can trigger risk-displacement processes among different organisations that create nil (or negative) 'public value'. Such processes

\footnotetext{
15 There is also increasing awareness in the business sector of the pitfalls of inappropriate business risk management (for instance, mechanistic quantification and aggravation of blame cultures).

${ }^{16}$ See Bardach 1999.
} 
can result in the greatest exposure to risk being borne by organisations that are politically weakest rather than those best placed (through knowledge or resources) to assume responsibility for risk. ${ }^{17}$

3.3. Risk management can also be used to deflect blame without creating public value if it is applied in a mechanical or tokenistic way. Public organisations often respond to disturbances in their environment by applying new procedures in ways that reflect what is readily doable or protects existing operations, rather than what adds public value. ${ }^{18} \mathrm{~A}$ classic example is Blau's case of US welfare agencies that encouraged dependency rather than independence in their clients in order to boost their performance ratings. ${ }^{19}$ Risk management if inappropriately applied can serve as a fig-leaf for policy inaction (for example where a business risk assessment paper trail can be used as a procedural defence for lack of substantive action), or as an excuse for sticking to procedural rules that may be ill-adapted to particular problems. And what may in some cases be the proper role of public organisations as risk-bearers of last resort in society may be hard to fit into conventional business-risk management ideas.

3.4. Inappropriately applied business risk management approaches could also be used to undermine other public sector values, notably transparency and learning from experience. Contemporary business doctrine on risk management stresses obligations to report system audits to stockholders, increasing pressures for transparency in one sense. But risk management approaches that were designed $\mathfrak{b}$ induce public organisations to behave more like private corporations in limiting blame or liability for errors could exacerbate existing tendencies by public authorities to restrict the publication of information about errors or malfeasance. ${ }^{20}$ To the extent that that happened, it would also further obstruct processes of learning from mistakes that need to build on such information.

\footnotetext{
17 As in the classic use of 'unacknowledgeable means' where states have traditionally used disavowable instruments in high-risk operations.

18 See Clay and Schaffer 1984; Ba rdach 1979.

${ }^{19}$ See Blau (1955).

${ }^{20}$ As it is, outsourcing of services to commercial suppliers and the use of commercial insurers of risks rather than the tradition of self-insurance by public authorities means that the release of information is frequently attended by considerations of business risk.
} 


\section{Figure 2. Three Potential Pitfalls of Inappropriate Business Risk Management in} Government

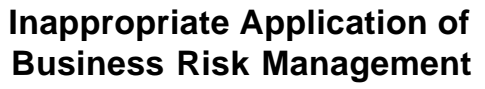

Inappropriate Application of
Business Risk Management
Potential Undesirable

Consequence
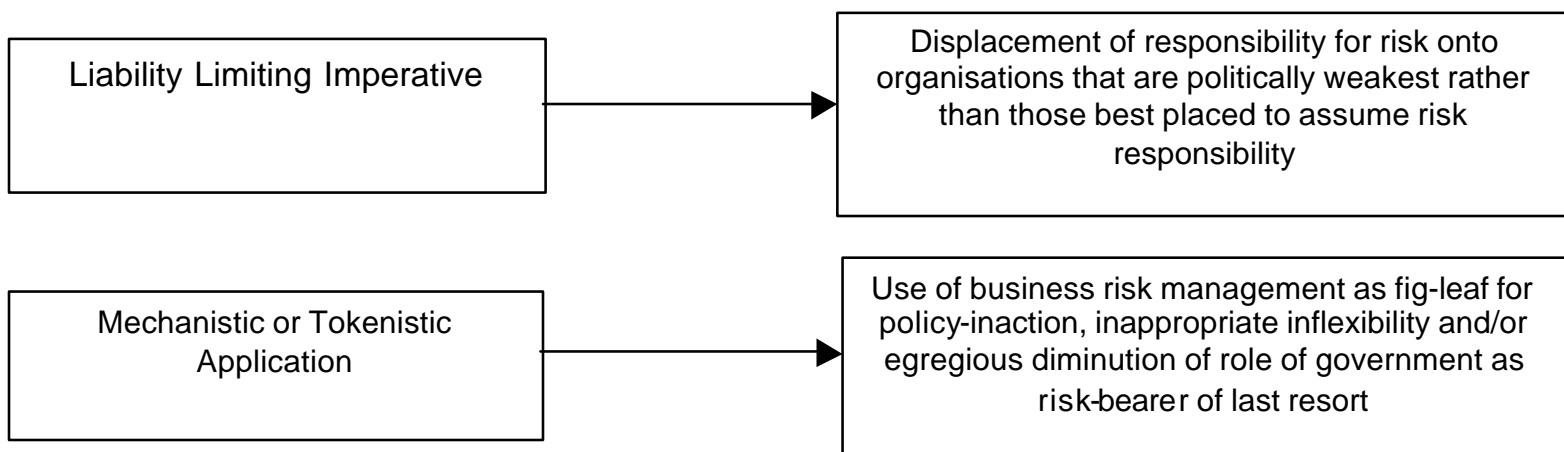

Use of business risk management as fig-leaf for policy-inaction, inappropriate inflexibility and/or egregious diminution of role of government as risk-bearer of last resort

Unbalanced Application

Use of business risk management as a 'Trojan Horse' to undermine other public sector values, notably transparency and learning

\section{Implications for Good Practice}

4.1. Business risk management in government needs to be designed to minimise negative side effects such as those discussed earlier, because the risks from poorly conceived or applied risk management systems are not trivial. No authoritative guide to good practice in public sector risk management yet exists, but at least three implications for good practice can be tentatively identified (see Figure 3), and they are also illustrated in the 'street festival' example given at the end of this paper.

(a) 'Getting the Whole System in the Room.' One is the need for procedures aimed at 'getting the whole system in the room' (Bunker and Alban 1997) rather than having risk management dictated by partial bureaucratic geography and associated imperatives of institutional blame avoidance. ${ }^{21}$ 'Getting the whole system in the room' is a recipe often applied to the handling of complex and conflictual policy issues. It means going beyond the integrated business risk management approaches used in corporations $\mathfrak{b}$ a cross-organisational focus, bringing together all the systems and organisations responsible for setting targets, for gathering information and for affecting behaviour or enforcing rules. It is often difficult to achieve, since as noted above public-policy risks are typically handled at different institutional and

\footnotetext{
${ }^{21}$ The relatively integrated approach to managing risks associated with released sex offenders mentioned earlier is an example of an attempt to follow this practice.
} 
constitutional levels. ${ }^{22}$ A risk management system that cannot 'get the whole system in the room' is unlikely to be more than a palliative.

(b) Focusing on Systemic Risk. Second is a need for procedures focusing on the management of systemic risk to public services rather than organisational blameavoidance through excessive emphasis on risk to particular organisations. As noted earlier, 'systemic risk' (a term often used in financial management) means risk affecting a whole industry or service, as distinct from risks to the position of any individual organisation. In some cases a service focus will neatly - or nearly - map onto the boundaries of an organisation, but frequently that will not be the case. In some cases (like health care) policy responsibility over systemic risk is placed at a different organisational level from responsibility for the risk faced by individual public organisations, and information-sharing among the different organisations is consequently crucial to the effectiveness of risk management at both levels. Risk management systems that sideline systemic risk issues may unintentionally weaken rather than strengthen overall risk management in government.

(c) Focusing on Intelligent Deliberation. Third is a need for business-risk management procedures that foster intelligent and sustained deliberation over risk rather than unreflective routinization in a tick-the-box style. That means designing deliberative procedures that require careful attention to be paid to likely second-order effects as well as first-order effects of risk management, and to 'reflective practitioner' processes. ${ }^{23}$ Procedures for assessing clinical systems and processes in health care are examples of routines aimed at intelligent deliberation among reflective practitioners, and the same goes for procedures like $\mathrm{HAZOP}^{24}$ in the chemical and engineering world. Such procedures to be effective need time, trust and local commitment. They require careful thought about the balance between open and confidential discussion, between discussion restricted to professionals and wider public participation, and between proceduralised or legalistic approaches and more informally-structured risk management discussions.

4.2. Business risk management is emphatically not a panacea for solving all the intractable polyvalent policy problems faced by government (sometimes referred to as 'wicked problems'). ${ }^{25}$ Nor is it something that can effectively be done by numbers in an unreflective way. Top business leaders often stress that risk management is an art or craft. And in some conditions, as argued earlier, risk management procedures could unintentionally exacerbate blame-avoidance tendencies in public bureaucracies. Achievable successes are likely to be limited and in the middle range. But, as was suggested earlier, intelligently applied business risk management approaches have the

\footnotetext{
${ }^{22}$ For example, it is commonly said that many inappropriate military purchasing decisions in the USA (overordering of materiel that is not needed) tend to stem from the horse-trading in Congressional committees designed to bring work to key electoral districts rather than errors by senior military professionals. 'Getting the whole system in the room' is impossible to achieve in this case.

${ }^{23}$ By second-order effects we mean the obligation and capacity to think about unintended side or reverse effects of risk management decisions, and to think at the system level. For example, the possibility that system engineers might deliberately choose to turn off all the plant's safety systems was not on the fault tree for the illfated Chernobyl nuclear power plant.

${ }^{24}$ HAZOP (Hazard and Operability Study) is a systematic and critical procedure for identifying hazards that might arise through the malfunction of any component of a system under investigation (see Kletz 1986).

25 See Churchman 1967.
} 
potential to increase public value by helping to ensure the continuity and quality of public services.

Figure 3. Implications for Good Practice

Pitfall to be avoided in application of business risk management in

Possible solution government

Blame-shifting rather than overall problem-solving
Develop procedures to 'get the whole system in the room

Excessive concentration on organisational risk at the expense of government-wide or social risk

Develop procedures to focus on systemic risk as well as organisational risk

Mechanistic or tokenistic application of business risk management

Develop procedures for intelligent deliberation considering second-order effects as well as first order effects 


\section{References}

Anderson, R (1999) 'A Framework for Strategy' in Risk and Regulation, supplement to LSE Magazine December 1999: 11.Bardach, E (1999) Getting Agencies to Work Together, Washington, Brookings Institution.

Bardach, E (1979) The Implementation Game, Cambridge, Ma, M.I.T. Press.

Barzelay, M with Armajani, B (1992) Breaking Through Bureaucracy, Berkeley, University of California Press.

Blau, P M (1955) Dynamics of Bureaucracy, Chicago, Chicago University Press.

Brennan, G (1991) 'Civil Disaster Management: An Economist's View' Canberra Bulletin of Public Administration 64 (May 1991): 30-3.

Bunker, B B and Alban, B T (1997) Large Group Interventions: Engaging the Whole System for Rapid Change, San Francisco, Jossey-Bass.

Churchman, C (1967) 'Wicked Problems' Management Science 4 (14): 141-2

Clay, E J and Schaffer, B B (1984) Room for Manoeuvre, London: Heinemann.

Dunsire, A (1978) The Execution Process Vol II: Control in a Bureaucracy, Oxford, Martin Robertson.

Durodie, B (1999) Poisonous Dummies: European Risk Regulation After BSE, London, European Science and Environment Forum.

Frei, D and Ruloff, D (1989) Handbook of Foreign Policy Analysis, Doredrecht, Martinus Nijhoff.

Hanley, M., (1999) Integrated Risk Management, London, LLP Professional Publishing

Health and Safety Executive (1996) Use of Risk Assessment within Government Departments. Report prepared by the Interdepartmental Liaison Group on Risk Assessment, London: HSE

Health and Safety Executive (1998) Risk Assessment and Risk Management: Improving Policy and Practice within Government Departments. Second report prepared by the Interdepartmental Liaison Group on Risk Assessment, London: HSE

Hood, C (1996) "Where Extremes Meet: "SPRAT" Versus "SHARK" in Public Risk Management' in C. Hood and D.K.C. Jones (eds) Accident and Design, London, UCL Press: 208-27.

Horlick-Jones, T. and Rosenhead, J. (2000) 'Developing decision Support for Risk Management in the Real Corporate World'. Risk and Human Behaviour: Newsletter of the ESRC Research Programme on Risk and Human Behaviour. Issue 6. pp.6-10. Swindon: ESRC

ICAEW (1999) Internal Control: Guidance for Directors on the Combined Code, London, Institute for Chartered Accountants for England and Wales.

Kletz, T A (1986) Hazop and Hazan: Notes on the Identification and Assessment of Hazards, London, Institution of Chemical Engineers.

Moore, M (1995) Creating Public Value, Cambridge, Ma, Harvard University Press

NHS Executive (Controls Assurance Team) (1999) Governance in the New NHS: Background Information and Guidance on the Development and Implementation of Controls Assurance for 1999/2000, Leeds, NHS Executive.

Power, M K (1999) 'The New Risk Management' inaugural lecture of P.D. Leake Professor of Accounting and Director of CARR, December 1999.

Royal Society (1992) Risk: Analysis, Perception, Management, London, Royal Society. Shrader-Frechette, K S (1991) Risk and Rationality, Berkeley, University of California Press. Tritton, P (1999) 'Risk Indus try Sees Knowledge Future' in Risk and Regulation, supplement to LSE Magazine December 1999: 15. 


\section{Example: Risk Management of Street Festivals}

Ethnic and other street festivals are common events in big cities across the world. They can bring immediate economic benefits to the host city as well as less tangible or longer-term benefits (like putting the host city on the cultural map, inter-ethnic bonding, or simply collective pleasure). But they also present financial risks to organisers and funders, since parades on public streets are free for anyone to watch. And they present other interrelated risks too, like risks of crowding, crime and public order, transport congestion and public health. Those upside and downside risks form part of the business risks faced by the many different public organisations involved in such events, for instance funding and local development bodies, police and emergency services, transport utilities and municipal authorities.

Events of this type pose a particular challenge to risk management, since in many cases they have grown up incrementally over time from informal or spontaneous beginnings. If each of the public organisations involved applies a standard business risk management approach to its part in such events in isolation from the others, the result may be efforts to pass financial or other risks from one institution to another (for instance if subway stations are closed to prevent crowding, the result may be increased congestion above ground or for other transport operators). Moreover, measures taken by one organisation to limit its downside business risk (for instance, insistence on levying a substantial bond on festival organisers by other public organisations) may unintentionally produce a broader system failure, in preventing the event from taking place at all or causing it to migrate to another location. Considerations of short-term blame-avoidance may outweigh longer-term benefits or lead to restriction on information about decisions and processes.

To avoid such potential pitfalls of business risk management in public services, it is necessary to conduct a risk analysis at the level of the project or event as a whole as well as at the level of the various public organisations involved. That involves an interactive forum or network permitting mutual adjustment of the business risks faced by the various players. It also requires the development and use of ways of intelligently mapping the interactions among the different elements of the overall system, for instance by use of the sort of 'soft systems methodology' developed by Horlick-Jones and Rosenhead (2000). Careful attention needs to be paid to possible second-order effects of risk management decisions, such as the possible emergence of alternative free festivals springing up in response to measures to control the risks of established festivals (for instance, by making them secure all- ticket events).

This paper was funded and published by the National Audit Office as part of the report by the Comptroller and Auditor General "Supporting Innovation: Managing Risk in Government Departments" (HC 864, 17 August 2000). The full National Audit Office report and other NAO material can be accessed from the NAO website (http://www.nao.gov.uk). (C) This article is subject to National Audit Office Copyright. 
Published by the Centre for Analysis of Risk and Regulation at the London School of Economics and Political Science

Houghton Street

London WC2A 2AE

(C) National Audit Office, 2000

ISBN 0753014297

All rights reserved.

No part of this publication may be reproduced, stored in a retrieval system, or transmitted, in any form or by any means, without the prior permission in writing of the publisher, nor be otherwise circulated in any form of binding or cover other than that in which it is published and without a similar condition including this condition being imposed on the subsequent purchaser.

Printed at the London School of Economics and Political Science, October 2000 